\section{The Reality Gap - How Enterprises Perceive Intercultural Management}

\author{
Gabriele Abermann FH-Prof. Mag. Dr \\ Fachhochschule Salzburg GmbH \\ Salzburg University od Applied Science \\ gabriele.abermann@fh-salzburg.ac.at
}

\author{
The Reality \\ Gap - How \\ Enterprises \\ Perceive \\ Intercultural \\ Management
}

\begin{abstract}
:
Purpose - The article documents the findings of semi-structured interviews with human resource managers and project leaders, mostly from Austrian enterprises, on their attitude towards the relevance of intercultural management and the measures they have taken to address this issue.

Methodology/Approach - The interviews were conducted in the context of the EU-funded university-enterprise project SKILL2E, aimed at designing and promoting cultural mentoring at the enterprise as a means to sustainably raise awareness and competence for an increasingly globalized workforce.

Findings - While a large majority attested to the relevance of intercultural management, only a small portion actively engaged in activities to recruit and integrate employees with diverse backgrounds. Additionally, a number of enterprises indiscriminately equated induction or buddy programmes with cultural mentoring. It also became evident that the potential of transnational student placements as a recruiting instrument and a learning opportunity for both universities and enterprises has not yet been fully realized.

Originality / Value - This case study demonstrates the gap between the perception and attitudes of enterprises in regards to diversity issues and the actual implementation status.

Keywords - human capital, globalization, intercultural competence, mentoring, sustainability, higher education.

Paper Classification - Case Study.
\end{abstract}

\section{Introduction}

This paper documents the findings of 65 enterprise interviews focusing on the integration of employees and work placement students with diverse cultural backgrounds. The interviews were carried out between November 2011 and December 2014. This case study was initiated and partly carried out within the context of the EUfunded university-enterprise project SKILL $2 E^{1}$ with members from Austria, Finland, Romania, Spain, Turkey, UK and US. The consortium comprised seven universities and five enterprises as well as a number of associated enterprises in these countries. The project participants came from diverse fields ranging from business, tourism, language studies, education, forest technology and IT to consulting, the service industry as well as a chamber of commerce. The main objective of the project was to

1 A detailed description of the project and all reports can be found at www.skill2e.fh-salzburg.ac.at.

\section{Psynepria}

International Journal of Synergy and Research Vol. 4, No. 1, 2015 p. $39-51$ 
IJSR 4,1 design a support structure for students to sustainably secure the added value of a work placement abroad.

From the university experience it was evident that students were well supervised in terms of their domain-specific knowledge and skills in their work placements. However, there was little focus on leveraging the skills gain through exposure to another culture and even less through dialogue between universities and enterprises on how to address this issue. Recently, it seems, not least through our project results, that attention is shifting towards quality aspects in student mobility and how the acquisition or enhancement of transversal skills can be measured, secured, and properly capitalised on in the labour market (Brandenburg, 2014; CIMO, 2014; Colucci et al., 2014; EMA, 2014; Ripmeester, 2014).

A main tenet of the SKILL2E project was to involve all three stakeholder groups university staff, students, enterprises - in designing any supportive measure intended to facilitate practical implementation, to consider enterprise reality, and thus to provide sustainability beyond the project life time. In the SKILL2E project, preparatory and post-mobility workshops as well as a guided intercultural reflective diary, the use of an assessment instrument and cultural mentoring at the enterprise side were identified as effective intervention measures. At the time of the project start in 2010 , there was no evidence that cultural mentoring had been already high on the agenda in European enterprises. In order to get a closer insight into current practices, additional enterprises were interviewed on their attitude towards a culturally diverse workforce apart from those which were already part of the consortium or had participated in project workshops.

\section{Methodology}

As the consortium actively involved enterprises at all project stages, it was neither seen as relevant nor feasible within the two-year project life time to carry out a systematic survey on the issue of the integration of a diverse workforce. Getting a snapshot of the enterprise's practices in each consortium region was, however, regarded as useful for the design of the SKILL2E Model. Therefore, it was decided to use semi-structured interviews with pre-formulated questions that all involved consortium members agreed on during a project meeting. The objective behind this approach was threefold: i) in line with the principle of involving all stakeholders, the interviews were carried out in most countries by students and documented in transcripts; ii) apart from the consortium, students were thus able to raise their own awareness and sensitivity towards issues of diversity; in the case of part-time students, sometimes even in their own companies; iii) a closer personal contact with these enterprises was seen as an opportunity to identify enterprises that might be interested in participating in the project in workshops, as associated partners or in offering placements for international students.

The interview questions agreed upon by the consortium, focused on the existence and concept of (cultural) mentoring, the integration practices of new employees and potentially international students, the role of diversity management, and the use of assessment instruments in this context. In Austria, the interviews were carried out as 
part of an assignment in the course Cross-cultural Management, held by the Author herself, in the Master programme Business Administration at the Salzburg University of Applied Sciences. The questions were translated into German by the Author of this paper and students had already acquired background knowledge on fundamentals of culture, intercultural communication and cross-cultural management before conducting the interviews. They had also received information on the SKILL2E project. Students were advised to basically keep within the limits of these questions but were free to ask for further details or related aspects. The majority of the students did not ask additional questions as the transcripts show.

Students could select their interview partners themselves provided that these would either be human resources managers or in a related position where they would actively be confronted with these issues in their daily business. No other criteria or restrictions on enterprise selection would be applicable. The rationale behind this approach was to increase student initiative and motivation. As mentioned above, in a number of cases part-time students actually interviewed representatives of their own companies.

The following figures show the geographical distribution and the business sectors of the interview partners. As can be seen in Figure 1, most enterprises are located in the greater Salzburg region (not including the neighbouring Germany). The vicinity and/or student home towns account for roughly $14 \%$ of interview partners from Germany, which, with a few exceptions, were also in the Bavarian border region to Salzburg. Two companies are South Korean due to the fact that one exchange student from Korea participated in the course and one part-time student works for a Korean company. About $30 \%$ of the Salzburg-based enterprises were part of an international group. Figure 2 confirms that the sectors the companies operate in, reflect the typical mix of the Salzburg region with the service sector and its various subcategories are quite prominent. Companies also varied much in size, but with a substantial portion in the SME range.

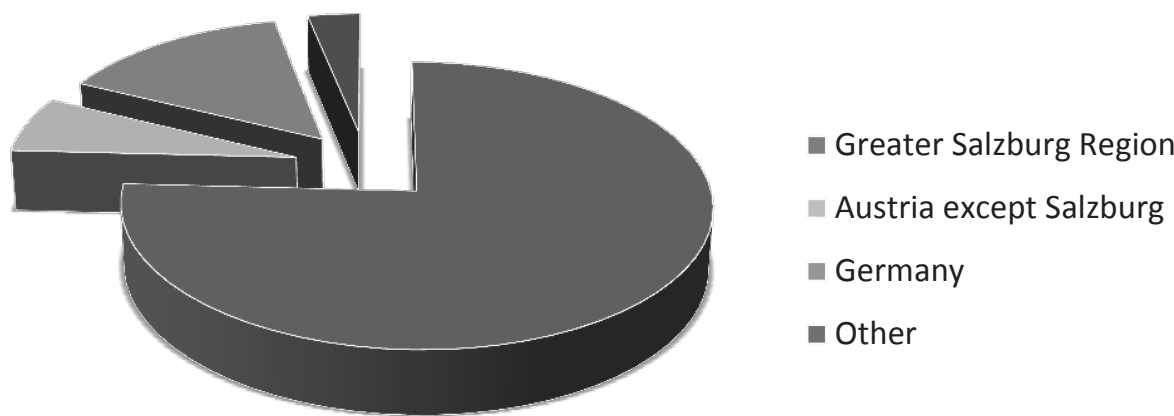

The Reality

Gap - How

Enterprises

Perceive

Intercultural

Management 


\section{IJSR}

4,1

Figure 2:

Enterprise sectors represented

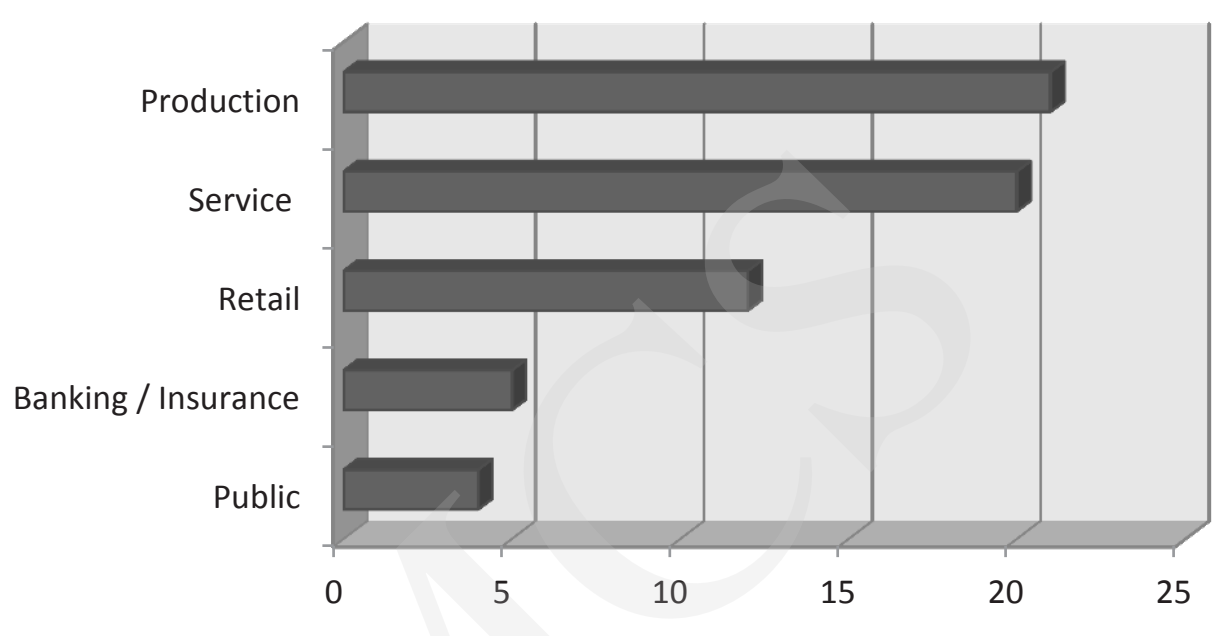

In line with the interview instructions, the majority (almost $40 \%$ ) of the interview partners were human resources managers. Slightly over $20 \%$ comprised CEOs, respectively branch managers or company owners. The rest were mostly department heads or project leaders.

\section{Findings}

The following sections provide an overview of the most relevant findings. As these are based on interview transcripts, mostly in German, statements have been grouped according to their general idea, not their exact original wording.

\subsection{Mentoring and new employee integration}

In the interviews, enterprises were asked, if they had an active mentoring programme. On purpose, no definition of mentoring was provided. Almost half of the enterprises $(45 \%)$ indicated that they had one. When asked to provide details of this mentoring scheme, it was obvious in ten cases that this was an induction programme or personal coaching, not mentoring in its true sense (Connor and Pokora, 2009; Conway, 1998; Meginson and Clutterbuck, 2005; Ragins and Kram, 2007; Shea, 2001). Thus, the percentage of enterprises in this sample offering mentoring is less than $30 \%$. As in some cases no details were documented, this figure might actually be even lower. In only two cases, the mentoring scheme was explicitly related to ethnic diversity. In the other cases, mentoring referred to career advancement, mostly for high potentials, executives or women. Over half of the interviewees, regardless whether they thought they had an active mentoring programme or not, mentioned the integration of new employees and conflict solving as situations where mentoring would be relevant. Career development was only mentioned by $14 \%$ as it can be seen in Figure 3 . 


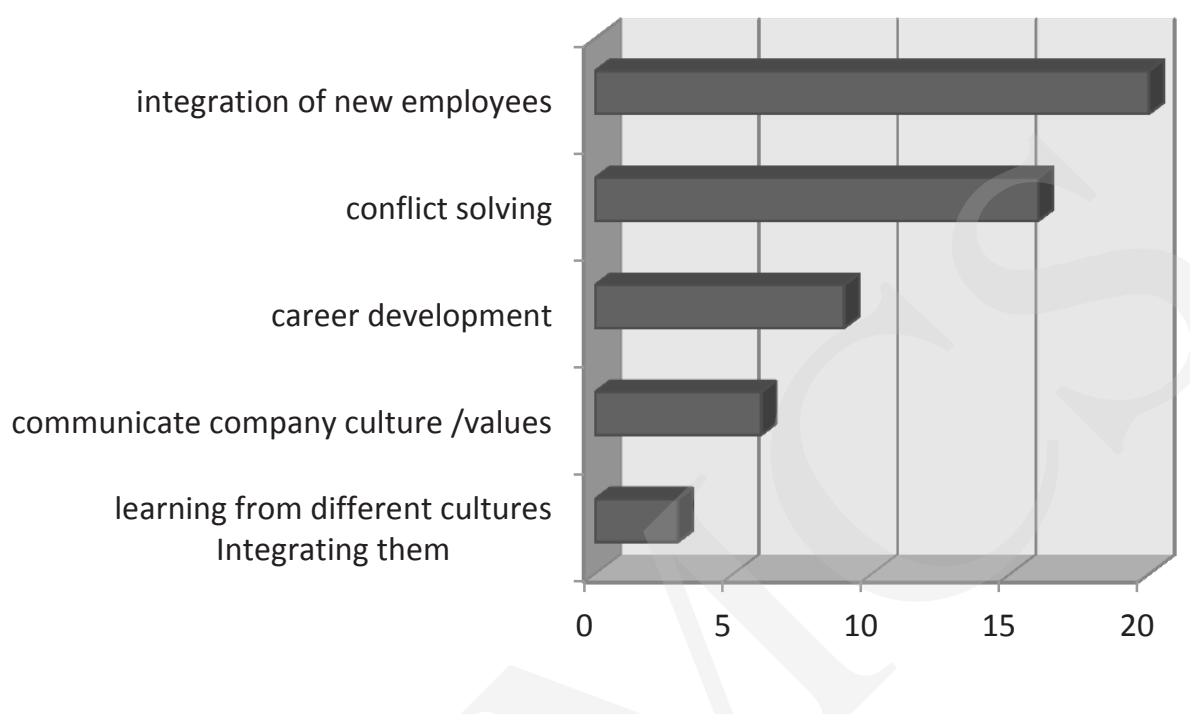

The Reality

Gap - How

Enterprises

Perceive

Intercultural

Management

Asked what they associated with the term 'Cultural Mentoring', over half of the interview partners referred to better understanding of other cultures, effective communication among these or synergistic use of cultural diversity. Communicating the local or company culture to employees with a different ethnic background or the support for these employees was mentioned by roughly a third. Further statements, each below $5 \%$, included developing intercultural or language skills, respecting different cultures, minimizing conflict, equal treatment or minority mentoring. 5\% said they had no idea what such a concept could involve.

\subsection{Work placement offers for international students}

As Figure 4 exemplifies, almost $70 \%$ of the enterprises offer work placements for international students and in quite a number of cases, students from specific countries are preferred. In these cases, the desired country of origin is related to business connections, mostly major or intended new markets, location of branches or important cooperation partners. Recruiting among a wider talent pool was also mentioned as a motivating factor. Countries named were the EU-members Finland, France, Germany, Spain, and the UK as well as China, Hong Kong, Russia, Serbia, and the USA. An interesting facet was mentioned by a German retailer who stated that placement students must wear culturally neutral attire. So, they would, for example, not be permitted to wear a head scarf.

In terms of integrating students into the enterprise, only few interview partners commented on this aspect. Of those who did, almost all mentioned that it was the immediate superior who would introduce the students to their tasks. One interview partner stated that students only have access to a more comprehensive support or even mentoring if it is already certain that the student stays in the company after graduation. It can be assumed that other enterprises also think along these lines. Among the reasons 


\section{IJSR}

4,1

Figure 4:

Work placement offers for international students

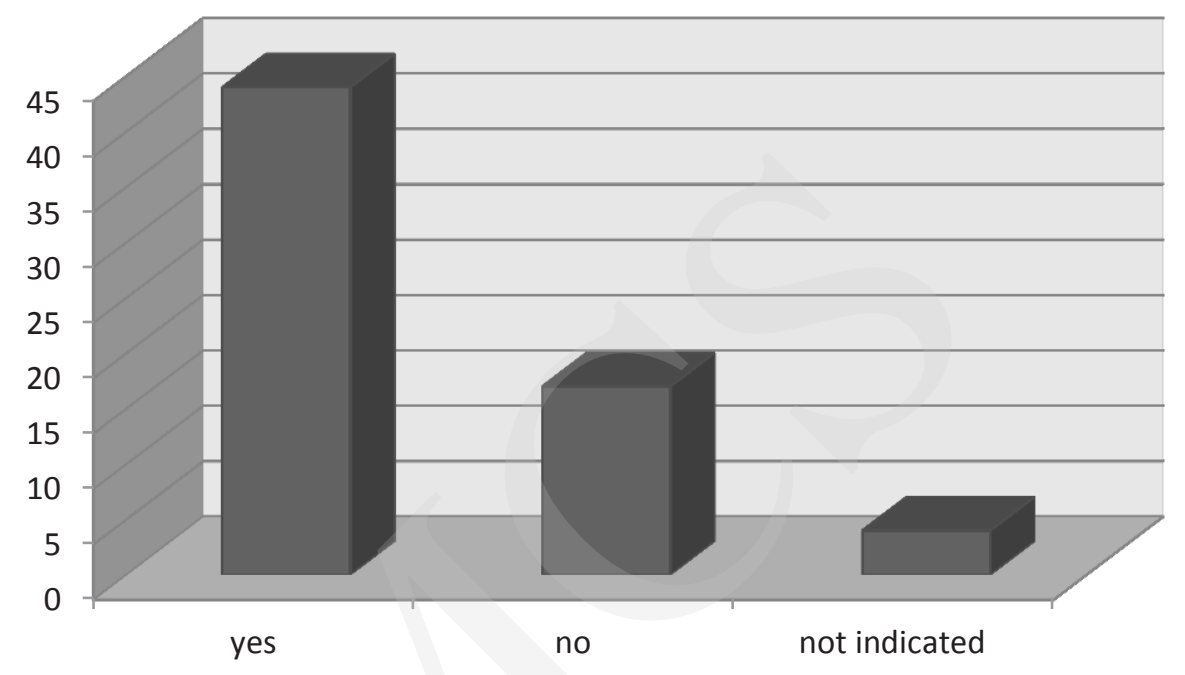

mentioned for not offering work placements for international students were: small size of the company, lack of resources, language barriers, no appropriate projects or no work placement offers in general.

\subsection{The role of and approach towards diversity}

Of all enterprises interviewed only five, respectively $7.5 \%$, reported that their staff do not include employees with a culturally diverse background. The countries of origin of the diverse workforce cover a wide range, in one case up to 160 nationalities. As Figure 5 demonstrates, there is a strong focus on Eastern and South-Eastern Europe including Turkey among those countries explicitly mentioned. This is not surprising as Austrian enterprises have been very active in that region, especially after the fall of the Communist regimes and the opening of the markets there. Austria also has traditionally often acted as a hub between the East and the West. Rather unexpectedly, Asia-Pacific countries including China, India, Pakistan, the Philippines, or Australia constitute the second-largest group. Interestingly, one interview partner referred to the company's diverse workforce not only in terms of ethnicity but also religion and sexual orientation. While no question was asked with respect to the positions of the culturally diverse workforce, there were, on the one hand, references to either low-level positions, such as cleaning, warehousing or construction or, on the other hand, to high potentials or managerial jobs.

Almost $90 \%$ of the interviewed managers regard a diverse workforce as an advantage. Figure 6 lists the reasons for this attitude. Improved communication and client service (30\%), getting or integrating different perspectives $(31 \%)$ and a better understanding of other cultures $(24 \%)$ were among the most often mentioned reasons. $9 \%$ attributed this fact to the labour market situation, again both at the low and highlevel ends of job ranges. 

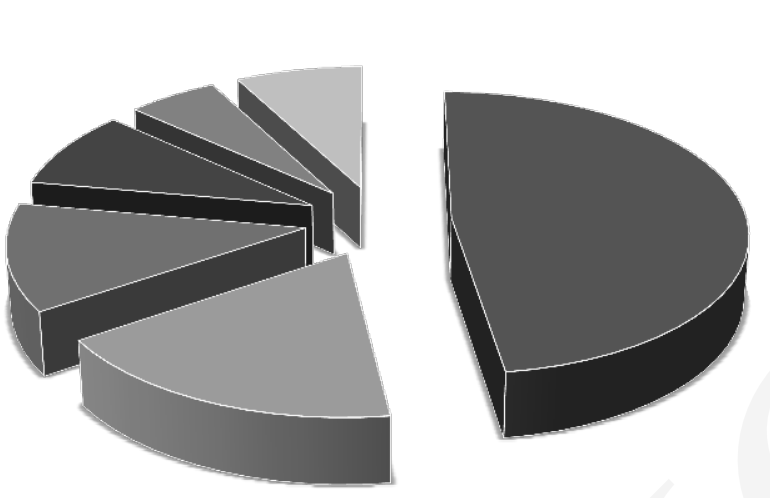

- Eastern and Southern

European

- Asia Pacific

- South America (mostly Brazil)

- UK

US

Africa

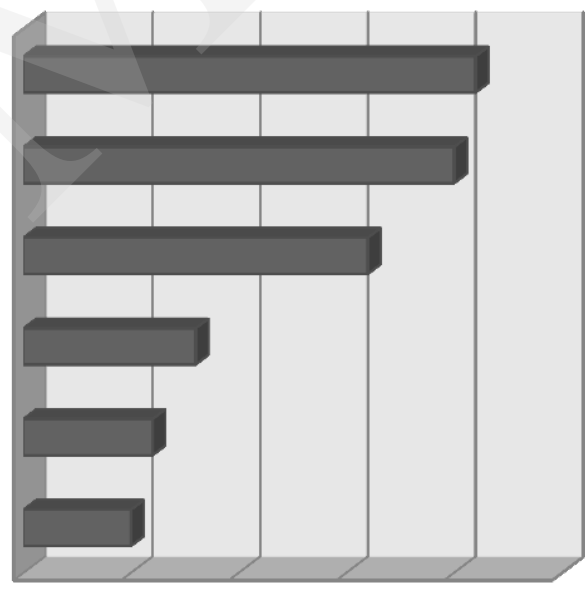

$\begin{array}{llllll}0 & 5 & 10 & 15 & 20 & 25\end{array}$ better client communication and service

different view points / perspectives

understanding other cultures

language skills

recruiting necessity

problem solving / increased competence

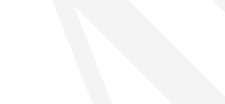

The Reality

Gap - How

Enterprises

Perceive

Intercultural

Management

Figure 5:

Countries of origin of diverse workforce

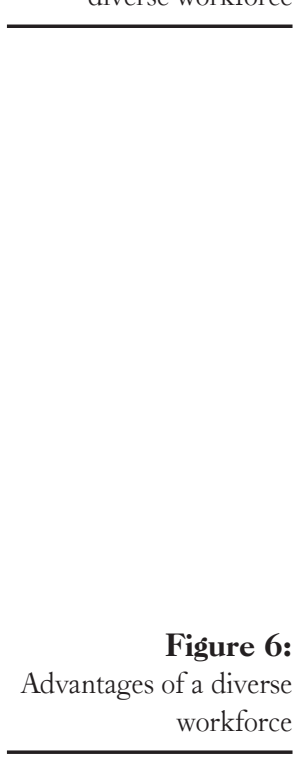

Only three interview partners clearly denied an advantage to diversity on the grounds that in recruiting, such differences are not relevant, only the job qualification matters. In contrast to the general positive attitude towards diversity, only $60 \%$ see a role for diversity management. Even fewer reported that they have actually already taken any concrete measures, some said that they have just started or are planning to address this issue. The small size of the enterprise, a lack of time and the already used argument that only the motivation, qualification or performance counts, were given as reasons.

As mentioned above, in the SKILL2E project an assessment instrument, the Intercultural Development Inventory (Abermann and Eder, 2012; Hammer, 2009; Hammer, 2011), was used to measure the change in orientation towards other cultures after a work placement abroad. The consortium, therefore, wanted to find out, whether 


\section{IJSR}

4,1

\section{Figure 7:}

Number of enterprises using an assessment instrument

\section{Figure 8:}

Number of companies expressing interest in an assessment instrument
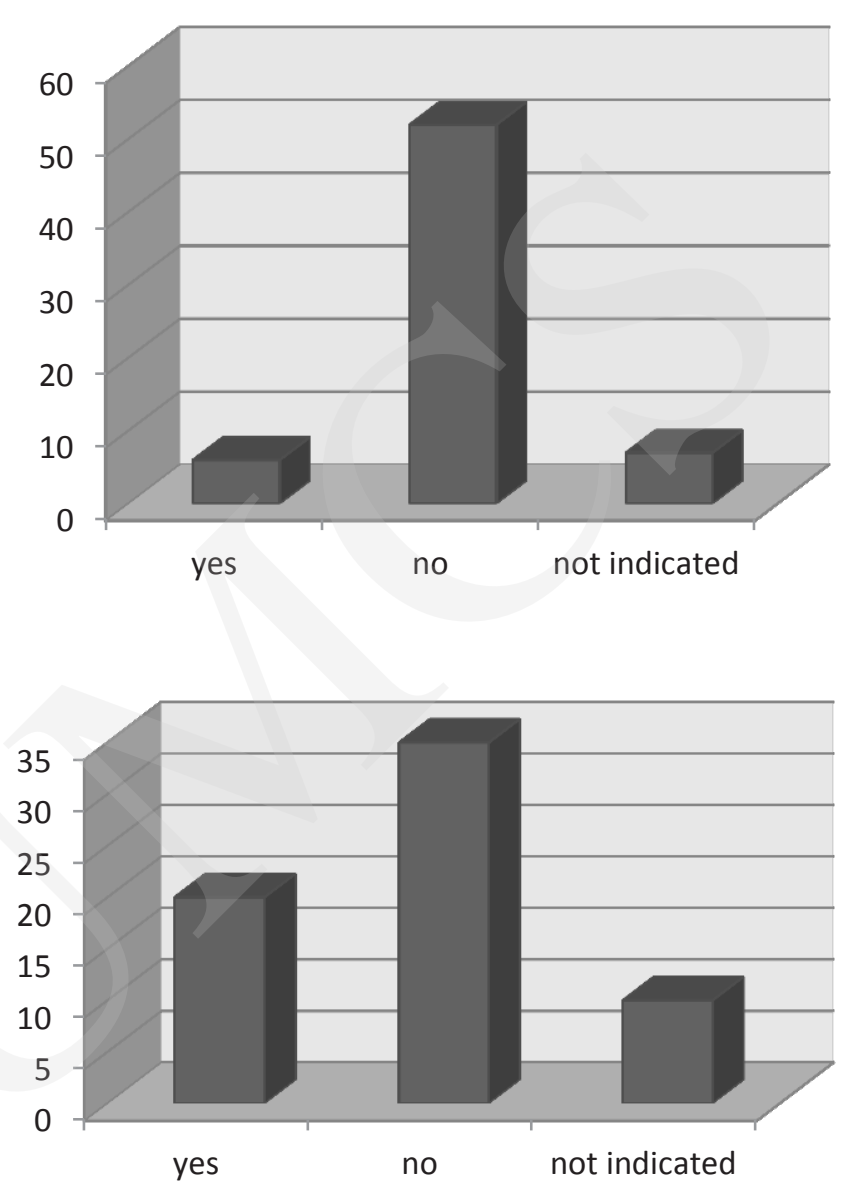

any such instruments were already common business practice. Figures 7 and 8 document the actual usage of an assessment instrument, respectively the expression of interest in its future implementation.

As Figure 7 shows, only six enterprises confirmed that they use such an assessment instrument. Of these, three were described in terms of personal meetings and appraisal interviews, one referred to statistics on the number of female employees and one to a code of conduct test. Only one company evidently uses an instrument, the "Great Place to Work" survey, carried out by an external consultant that comprehensively addresses diversity. Roughly a third expressed interest in such an instrument, whereas only a few interview partners provided reasons why they were not interested in using one. In their opinion, culture cannot be measured, personal meetings are preferable or it

2 Details on this survey are available at http://www.greatplacetowork.com/our-services/assessyour-organization. 
would actually be discriminating against employees of a different ethnic origin, if such an instrument was used.

\section{Implications}

Considering the high percentage of enterprises with culturally diverse staff in the interview sample and the almost unanimous positive attitude towards cultural diversity, it is noteworthy that only few have actively already taken measures to address this issue or even to leverage the benefits as documented in two McKinsey publications (Barta, 2011; Hunt et al., 2014). According to these studies, enterprises with women or foreigners in their board have performed significantly better, especially during the economic crisis. Along these lines, the Vienna-based research institute IBW estimates the annual financial losses of Austrian enterprises when ignoring diversity and not utilizing the competences of employees with a migratory background at 7.7 billion Euros (Schmid, $2010 ; 2014)$. In a globalised economy and an increasingly heterogeneous society, it should be evident that even regionally operating smaller and medium-sized enterprises are confronted with cultural diversity, be it through suppliers, clients / customers or the workforce set-up.

On the basis of these interviews, it seems that there is a significant gap between attitudes of managers, who almost all see the benefits of diversity, and current organisational practices. Diversity management, which, of course, does not only relate to ethnic origin, but also to religion, gender, age, sexual orientation, physical ability, and race, has obviously not yet become mainstream. In the face of the demographic changes and the ensuing forecast of a lack of qualified workforce, it could be expected that Austrian enterprises would be more proactive in this respect. Lack of time or resources, reasons mentioned for not tackling this issue, seem rather short-sighted when considering long-term consequences.

Of those enterprises interviewed that are export-oriented and internationally operating or cooperating, however, the larger portion has already implemented some measures. Nevertheless, even among them there seems to be some confusion as to the kind of scheme they actually apply. Induction programmes, coaching and mentoring are often used indiscriminately. Equally, the goal of the measures does not always seem clear as reflected in a statement by one interview partner, who referred to the person acting as a mentor as "a colleague from the same department ...[who] helps to integrate as long as it's necessary, but actually it's not defined. In three months everything is ready and accommodated". ${ }^{3}$

Very few enterprises have established formal and structured mentoring schemes. In the majority of the cases, the support is confined to organisational and administrative aspects like finding accommodation or help in dealing with bureaucracy and authorities. This support is clearly valuable and there may actually be some informal mentoring going on, but its potential does not seem to be fully utilized.

3 This is the original wording as the interviewing student was an exchange student and the interview partner, though Austrian, agreed to use English for communication.

\author{
The Reality \\ Gap - How \\ Enterprises \\ Perceive \\ Intercultural \\ Management
}


IJSR 4,1
Furthermore, in many cases, the assigned person who supports the integration of new employees is quite often the immediate superior. Intertwining functional hierarchies and mentoring is not usually seen as conducive (Conway, 1998). Evidently, European policy-makers have paid heed to this fact as the new Erasmus+ learning agreement for traineeship ${ }^{4}$ testifies, which the sending university, the students and the enterprise must sign, when students do a work placement abroad. It is now required that the enterprise not only has to nominate a project supervisor, but additionally also a mentor. In the explanatory notes, it is stated that this mentor in the enterprise should not be an immediate superior. No data on the actual implementation are available at this point as this requirement has only been introduced in the academic year 2014/15. It is to be doubted that true mentoring will be offered to placement students, especially if companies do not foresee that the student will turn into a permanent staff member on graduation (see section 3.2 above). This is definitely understandable when seeing mentoring only as a one-way street, where the enterprise invests and the mentee profits. Where mentoring is seen as a learning process with mutual benefits (Matuszek et al., 2008) as was conceptualised in the SKILL2E project (Tigerstedt and Fabricius, 2012), the enterprise may also profit through building organisational intercultural competence and thus leverage the innovation and problem-solving potential of the wider range of perspectives of a diverse workforce.

Placement students could act here as intermediaries or as pilots, so that staff can get familiar with aspects of the student's culture, especially regarding communication and conflict patterns. Notwithstanding, individuals have their own specific personalities and never represent a culture as such, but the confrontation and active integration with "otherness" could gradually result in a more open and productive atmosphere. This may help attract young talents across national boundaries and thus better match labour shortage with job seekers. Those few enterprises in the interview sample, which have already been actively recruiting placement students with a view to building linguistic and intercultural competence, will certainly have a competitive edge over others.

Another result that was quite surprising was the fact that despite the plethora of quality management tools and the quantitative or qualitative indicators that enterprises use to assess their performance, only two companies reported the usage of any kind of diversity assessment instrument. Certainly, caution needs to be exercised in using such an instrument, as reliability and validity need to be given (Deardorff, 2009; Paige, 2004). However, when embedded in a comprehensive and strategic approach, such instruments may trigger and facilitate reflection, a basic skill in building intercultural competence (Deardorff, 2006) and may support documenting progress. Equally, these instruments may raise awareness and sensitivity for the advantages of cultural diversity, but also the necessity for actively addressing it. Ignoring or even finding it "discriminating", as one interview partner put it, to see cultural diversity as a relevant human resources factor prevents enterprises from reaping the benefits of diverse teams and having strategies in place to counter culturally induced conflict (Distefano and Maznevski, 2000; Lane et al., 2009).

4 This form is available at http://ec.europa.eu/education/opportunities/higher-education/doc/ learning-traineeships_en.pdf. 
So what is the role of universities in this setting? Universities can contribute here by sharing their research in this field. This will, however, only have an effect if the findings reverberate in the workplace reality and are translated into concrete, feasible and realistic measures. This will require policy-makers at regional, national and European levels as well as the worlds of research, education and work to cross boundaries and to cooperate. In the words of the Managing Director of Rold Group S.p.A, Ms Laura Rocchitelli, this means that "companies need to shift their 'lens' from a short vision to a long vision; that academia needs to become more open towards companies; that teachers have to be closer to companies so they understand business processes" (Andersen and Humpl, 2014, p. 27). Such collaborations have recently received more attention as reflected in the EU initiatives of the Business Forum or the Knowledge Alliances ${ }^{5}$. It is, however, not clear to what extent first results like the "Handbook for Cooperation" (Hague and Tirati, 2013) reach audiences outside the immediately involved enterprises and those that already cooperate well with universities.

\section{Conclusion}

As described in the methodology section, it has to be stressed that the enterprises interviewed do not constitute a representative sample, as they were selected by the personal preference of the student interviewers and not on the basis of defined criteria. Nevertheless, it seems safe to say that in the greater Salzburg region, the potential of cultural diversity has not yet been fully utilized. While recognizing the role of diversity, there seems to be a discrepancy between acknowledging its relevance and actually putting this knowledge into practice, not least the opportunities of mentoring in this context. Intensifying the dialogue between universities and enterprises, especially with regard to student placements, could be a driving force for facilitating the move forward in this direction. A recent impact study on university-business cooperation confirmed "that the bringing together of students and existing employees served to raise the knowledge levels of employees as well as students" (Healy et al., 2014, p. 40). European policy makers have started important initiatives with the Business Forum, the Knowledge Alliances or the new focus on transversal competence acquisition in student placements, but (pro-) active involvement and strategic, long-term thinking of enterprises and universities are called for to close this reality gap.

\section{References}

Abermann, G. and Eder, R. (2012), "Intercultural competence assessment", SKILL2E project report, available at: http://skill2e.fh-salzburg.ac.at/fileadmin/documents/Reports/SKILL2E_DEV0102_ Assessment_Instrument_Selection_Report_2012_05_31.pdf (accessed March 10, 2015).

Abermann, G. and Tigerstedt, C. (2012), "Cultural Mentoring - Challenges and opportunities: A trigger for sustainable intercultural competence gain in student placements abroad", in Dominguez, N. and Gandert, Y. (Eds.), 5th Annual Cultural Mentoring Conference

5 Information on the EU initiatives for university-business cooperation and related reports are available at http://ec.europa.eu/education/tools/university-business_en.htm. 
IJSR

4,1
Proceedings: Facilitating Developmental Relationships for Success, University of New Mexico, Albuquerque.

Andersen, T. and Humpl, S. (2014), "Proceeding report: Universities, businesses \& co: Together we can. Strategic Inter-sectoral partnerships for economic and social change and growth, Rome 2-3 October 2014", European Commission, Brussels, available at: http://www. ubcforum-italy.com/ (accessed March 10, 2015).

Barta, T. (2011) "Vielfalt siegt! Warum diverse Unternehmen mehr leisten", McKinsey\&Company, Köln, available at: http://www.mckinsey.de/sites/mck_files/files/Vielfalt_siegt_deutsch.pdf (accessed March 10, 2015).

Brandenburg, Uwe (2014), "The Erasmus impact study. Effect of mobility on the skills and employability and the internationalization of higher education institutions", European Commission, Brussels, available at: http://ec.europa.eu/education/library/study/2014/ erasmus-impact_en.pdf (accessed January 15, 2015).

Colucci, E., Ferencz, M., Gaebel, M. and Wächter, B. (2014), “Connecting mobility policies and practice: Observations and recommendations on national and institutional developments in Europe«, EUA, Brussels, available at: http://www.eua.be/px (accessed January 15, 2015).

Conway, C. (1998). Strategies for Mentoring, A Blueprint for Successful Organizational Development, John Wiley \& Sons Ltd, Chichester.

Connor, M. and Pokora J. (2009), Coaching and Mentoring at Work, McGraw Hill, Glasgow.

Deardorff, D. (2006), "Identification and assessment of intercultural competence as a student outcome of internationalization", Journal of Studies in International Education, 10, pp. 241-266. DOI: http://dx.doi.org/10.1177/1028315306287002

Deardorff, D. (2009). "Implementing intercultural competence assessment", in Deardorff, D. (Ed.), The Sage Handbook of Intercultural Communication, Sage, Thousand Oaks, CA, pp. 477-491.

Distefano, J. and Maznevski, M.L. (2000), "Creating value with diverse teams in global management", Organizational Dynamics, 29:1, pp. 45-63. DOI: http://dx.doi.org/10.1016/ S0090-2616(00)00012-7

EMA (2014), "Erasmus Mundus Graduate Impact Survey", available at: http://www.em-a.eu/ fileadmin/content/GIS/Graduate_Impact_Survey_2014.pdf(accessed January 15, 2015).

Hague, E. and Tirati, S. (2013), "Guidebook on cooperation models between the business world and educational providers", available at: http:/www.europemobility.eu/download/ publications/008-BOOK-A4-TC2-CooperationModels-web.pdf (accessed March 10, 2015).

Hammer, M. (2009), "The intercultural development inventory", in Moodian, M.A. (Ed.), Contemporary leadership and intercultural competence, SAGE, Thousand Oaks, pp. 203-217.

Hammer, M. (2011), "Additional cross-cultural validity testing of the Intercultural Development Inventory", International Journal of Intercultural Relations, 35, pp. 474-487. DOI: http:// dx.doi.org/10.1016/j.ijintrel.2011.02.014

Healy, A, Perkmann, M. Goddard, J. and Kempton, L. (2014), "Measuring the impact of university business cooperation", Publications Office of the European Union, Luxembourg, available at: http://bookshop.europa.eu/is-bin/INTERSHOP.enfinity/WFS/EU-BookshopSite/en_GB/-/EUR/ViewPublication-Start?PublicationKey=NC0214337 (accessed March $10,2015)$.

Hunt, V., Layton, D. and Prince, S. (2014), "Diversity matters", McKinsey\&Company, London and Atlanta, available at: http://www.mckinsey.com/insights/organization/why_diversity matters (accessed March 10, 2015).

Lane, H.W., Maznevski, M.L., Deetz, J. and DiStefano, J. (2009), International Management Behavior: Leading with a Global Mindset, 6th ed., Wiley, Hoboken, NJ.

Matuszek, T., Self, D.R. and Schraeder, M. (2008), "Mentoring in an increasingly global workplace: facing the realities and challenge", Development and Learning in Organizations, 22:6, pp. 18-20. DOI: http://dx.doi.org/10.1108/14777280810910311 
Megginson, D. and Clutterbuck, D. (2005), Techniques for Coaching and Mentoring, Elsevier Butterworth-Heinemann, Amsterdam.

Paige, M. (2004), "Instrumentation in intercultural training", in Landis, D., Bennett, J.M. and Bennett, M.J. (Eds.), Handbook of intercultural training, 3rd Ed., Sage, Thousand Oaks, CA, pp. 85-128. DOI: http://dx.doi.org/10.4135/9781452231129.n4

Ragins, B.R. and Kram, K.E. (2007), The Handbook of Mentoring at Work: Theory, Research, and Practice, Sage, Thousand Oaks, CA.

Ripmeester, N.(2014), “International businesses:Consumers of global talent?”, Internationalisation of Higher Education, Vol 1., pp. 22-34.

Schmid, K. (2010), "Außenwirtschaft \& Humanressourcen: Herausforderungen infolge der Internationalisierung", IBW, Vienna, available at: http://www.ibw.at/components/com redshop/assets/document/product/fb152.pdf (accessed March 10, 2015).

Schmid, K. (2014), "Mehrsprachigkeit und Internationalisierung: ungenutzte Potentiale?", Presentation at the conference 'Mehrsprachigkeit und Wirtschaft', Linz, 26 September 2014, available at: http://www.linz.at/images/Mehrsprachigkeit-Internationalisierung_Mag. Schmid_Linz.pdf (accessed March 10, 2015).

Tigerstedt, C. and Fabricius, S. (2012), "Cultural mentoring concept", SKILL2E project report, available at: http://skill2e.fh-salzburg.ac.at/fileadmin/documents/Reports/SKILL2E_ DEV0302_Cultural_Mentoring_Report_2012_06_30.pdf (accessed March 10, 2015).

\section{Biographic Notes}

Dr. Gabriele Abermann is Professor of English and Intercultural Communication at the Salzburg University of Applied Sciences. She has served as Vice Rector and as Director of International Relations and has been seminal in building the institution's partner network. Dr. Abermann holds a doctorate in English language and literature and has extensive teaching experience in Austria and abroad. She has coordinated the university-enterprise cooperation project SKILL2E, which aimed at enhancing the intercultural competence acquisition of students on transnational placements and intensifying the dialogue between universities and enterprises. She has also acted as a national Bologna and now EHEA expert.

\author{
The Reality \\ Gap - How \\ Enterprises \\ Perceive \\ Intercultural \\ Management
}

